\title{
HÁBITOS E SIGNIFICADOS RELACIONADOS À MÍDIA, FUTEBOL, COPA DO MUNDO E NACIONALISMO PARA ESTUDANTES DO ENSINO MÉDIO
}

\author{
Marcos Roberto Godoi
}

Faculdade Aum, Cuiabá, Mato Grosso, Brasil

\section{Larissa Beraldo Kawashima}

Instituto Federal de Educação, Ciência e Tecnologia de Mato Grosso, São Vicente da Serra, Mato Grosso, Brasil

\begin{abstract}
Resumo
Nosso objetivo foi compreender a relação dos alunos do Ensino Médio com a mídia, o futebol, a Copa do Mundo e o nacionalismo. Aplicamos um questionário para 120 estudantes de quatro turmas do $1^{\circ}$ ano do Ensino Médio do IFMT, campus São Vicente. Com base na análise dos dados, pudemos concluir que os estudantes têm o hábito de assistir jogos de futebol na TV, principalmente na Copa do Mundo, e praticam menos futebol (ainda que em percentual elevado) do que assistem. Os significados da Copa são paixão nacional, união, festa, paz, espetáculo, orgulho, obrigação de vitória.
\end{abstract}

Palavras-chave: Mídia - Copa do Mundo - Nacionalismo

\section{Introdução}

Omo em todo ano de Copa do Mundo, observamos na mídia uma
proliferação de discursos, imagens e sons que fomentam sentimentos de nacionalismo. À medida que a Copa se aproxima, durante e após, as publicidades exploram este tema. Nos telejornais um espaço considerável é destinado à cobertura da Copa, neles são apresentados a trajetória pessoal e profissional dos convocados, analistas comentam o desempenho da seleção, programas esportivos ganham edições extras. Revistas semanais apresentam matérias de capa relacionados ao evento. Nos jornais impressos, os cadernos de esportes ampliam seu número de páginas, cronistas comentam e analisam o grande evento. Várias empresas realizam sorteios de prêmios com perguntas relacionadas ao mundial de futebol. Tudo isto faz com que o futebol e a Copa entrem no cotidiano de milhões de brasileiros, mesmo daqueles que normalmente não se interessam muito por futebol, e contribui para que 
este evento esportivo seja altamente espetacularizado e mercadorizado.

Segundo Helal, Cabo e Silva (2010), o futebol é notadamente o mais influente elemento cultural de aglutinação no Brasil, ao contrário dos Estados Unidos, onde existem quatro esportes de massa: hóquei, baseball, basquete e futebol americano. De fato, em quase todo o mundo temos o futebol como esporte hegemônico. Em períodos de Copa do Mundo, os brasileiros despertam uma catarse coletiva, numa espécie de "nacionalismo cíclico". De acordo com Gastaldo (2000), na época do mundial, casas, ruas, fachadas de edifícios, lojas, shoppings centers e edifícios públicos são decorados nas cores rituais para celebração da nacionalidade: verde e amarelo. Em dias de jogos do Brasil há uma profunda alteração da vida cotidiana no país: acontece algo como uma espécie de tradição de "semi-feriado"; o horário bancário muda; estabelecimentos comerciais fecham; o trânsito das grandes cidades sofre alterações. Nos semáforos, vendedores ambulantes vendem fitinhas, chapéus, camisetas da seleção, cornetas, bandeiras nas cores nacionais.

Conforme Bittencourt (2009), o evento cíclico da Copa do Mundo exerce um verdadeiro fascínio na sociedade brasileira. A seleção brasileira de futebol, como principal protagonista deste evento, impregna o sistema de representações que partilhamos e tem seus efeitos sentidos em esferas como a economia, a religião, a família, o grupo de amigos, a política, a história, a educação e educação física. Para este autor, a Copa não é um simples jogo, ela não tem um fim em si mesma, mas através dela participamos de um jogo de identidades, pomos em jogo nossa brasilidade e nossa relação com o mundo.

Neste sentido, o tema desta pesquisa baseia-se na relação dos alunos do Ensino Médio com o futebol, a Copa do Mundo e o nacionalismo. Com base neste tema, levantamos a seguinte questão de pesquisa: Qual é a relação dos alunos do Ensino Médio com a mídia, o futebol, a Copa do Mundo e o nacionalismo? Em decorrência da pergunta, nosso objetivo central foi compreender esta relação, e especificamente analisar: a) os hábitos dos alunos em relação a mídia e o futebol (TV, jornais, revistas e internet); b) hábitos e significados em relação a prática do futebol; c) significados relacionados a Copa do Mundo e nacionalismo.

No que se refere à metodologia, esta pesquisa caracteriza-se por seu um estudo de campo. A amostra da pesquisa foi constituída por 
120 alunos (35 do sexo feminino, 85 do sexo masculino, com idades entre 14 e 19 anos) de quatro turmas de primeiro ano do Ensino Médio integrado do Instituto Federal de Educação, Ciência e Tecnologia de Mato Grosso (IFMT), campus São Vicente. O número elevado de sujeitos do sexo masculino participantes da pesquisa se justifica pelo fato do Ensino Médio ser integrado ao curso técnico em Agropecuária, uma carreira profissional com prevalência masculina.

No IFMT são ofertados além do Ensino Médio, o Ensino Superior e Pós-graduação latu sensu. O Instituto fica situado no município de Santo Antônio de Leverger - MT, na serra de São Vicente. Os estudantes moram em cidades vizinhas ou na zona rural e a maioria é proveniente do interior do estado, residindo na escola em regime de internato. Sobre o acesso dos alunos às mídias, eles têm a disposição dois laboratórios de informática com acesso a rede, com 25 computadores cada. Além disto, alguns alunos possuem seus próprios computadores com acesso a rede sem fio oferecida pela instituição, além de uma biblioteca com livros, revistas semanais e jornais impressos. Sobre o acesso à televisão, todos os quartos dos alojamentos internos ao campus possuem um aparelho, além da cantina da escola que conta com dois aparelhos com antena parabólica.

O instrumento de coleta de dados foi um questionário contendo perguntas objetivas e discursivas, preenchidos pelos próprios alunos. A coleta de dados foi realizada na própria escola, durante as aulas de Educação Física no período de 24/05 a 08/06 de junho de 2010. A análise foi desenvolvida com base no referencial teórico de estudiosos da Educação Física, Comunicação e Antropologia que se dedicam a esta temática.

\section{Análise e discussão dos resultados}

No que tange ao hábito de assistir futebol na TV, 112 (93,33\%) alunos disseram que têm este costume e $8(6,66 \%)$ disseram que não. Dos 112 que têm hábito, $48(42,85 \%)$ assistem sempre, 54 (48,21\%) as vezes e $10(8,33 \%)$ pouco. Semanalmente, ocorre a transmissão de jogos de futebol ao vivo dos principais campeonatos de clubes na TV aberta. Como se vê, a maioria dos alunos assistem futebol na TV, com os percentuais de frequência sempre e as vezes sendo os mais expressivos.

Em relação ao hábito de ler matérias sobre futebol em revistas, jornais ou internet, 94 (78,33\%) disseram que leem e 26 (21,66\%) não le- 
em. Dos 94 que leem, 16 (17,02\%) leem sempre, 52 (55,31\%) as vezes e $26(27,65 \%)$ pouco. Podemos perceber que os alunos que leem matérias sobre futebol, apresentam um percentual significativo, porém menos expressivo do que aqueles que assistem o futebol pelo TV. Além disto, a frequência de leitura tende ser maior as vezes, e não sempre.

Interrogados sobre o hábito de jogar futebol, 100 (83,33\%) disseram que sim e $20(16,66 \%)$ não. Entre os que têm o costume, 47 (47\%) jogam sempre, 40 (40\%) as vezes e 13 (13\%) jogam pouco. Podemos perceber que a maioria dos alunos costumam jogar futebol, com uma frequência de sempre e as vezes bastante significativa. Ainda assim, o hábito de assistir futebol pela TV é $10 \%$ maior do que o hábito de jogar futebol. Conforme Pires:

No campo da cultura esportiva, ao referenciar-se na vivência proporcionada pela mediação tecnológica por meio da indústria midiática em seu tempo livre, em detrimento da experiência formativa que pode ser oportunizada pelo esporte, o sujeito passou sucessivamente de praticante a espectador, deste a telespectador, e agora, a teleconsumidor (PIRES, 2003, p. 22).

Pires (2003) aponta a tendência do sujeito de ir aos poucos deixando de praticar esporte e passar a assistir aos jogos nos estádios, na TV e consumir produtos relacionados ao espetáculo esportivo (como camisas e acessórios de clubes futebolísticos, TV por assinatura para assistir jogos exclusivos em canais esportivos etc.). Deste modo, deixam de ser um sujeito ativo da prática de esporte e passa a ser mais sedentário e passivo do ponto de vista da prática esportiva.

Sobre os valores e significados da prática do futebol, 37 (30,83\%) dos alunos pesquisados afirmaram que o futebol promove saúde, bem estar e qualidade de vida; 33 (27,5\%) disseram que é um momento de lazer/diversão; $33(27,5 \%)$ relataram que o futebol promove trabalho em equipe, amizade e convivência em grupo; 24 (20\%) disseram que é bom para o preparo físico; $11(9,15 \%)$ expressaram que o futebol estimula o respeito as regras e aos colegas e trabalha valores éticos; 10 $(8,33 \%)$ afirmaram que o futebol promove valores de coragem, confiança, persistência e superação de limites; 5 (4,16\%) disseram que a prática do futebol ensina a ser competitivo, saber ganhar e perder; 4 $(3,33 \%)$ relataram que o futebol promove a educação e a cultura; 3 
$(2,5 \%)$ ressaltaram os valores estéticos que a prática do futebol pode trazer ao corpo; $2(1,66 \%)$ afirmaram que o futebol melhora a estima ${ }^{1}$.

Percebemos aqui uma polissemia de significados com diversos valores que os alunos associam a prática do futebol. No entanto, os mais destacados por eles foram saúde, bem estar e qualidade de vida; lazer e diversão e trabalho em equipe, amizade e convivência em grupo. Podemos dizer que estes valores estão mais associados a dimensão do esporte lazer e não do esporte competitivo. O que em se tratando de Educação Física escolar é um bom sinal, uma vez que os valores da dimensão do esporte competitivo já foi amplamente criticado na área específica quando aplicado à esfera escolar.

No que se refere ao hábito de assistir aos jogos da Copa na TV, 118 (98,33\%) disseram que assistem e $2(1,66 \%)$ não. Perguntado com quem assistem os jogos da Copa, dos 118, 92 (77,96\%) assistem com os amigos, 90 (76,27\%) assistem com a família, 4 (3,38\%) com desconhecidos e $1(0,84 \%)$ sozinho. Sobre aonde assistem os jogos da Copa, $99(83,89 \%)$ veem os jogos em casa, $36(30,50 \%)$ na rua ou em bares, $25(21,18 \%)$ na escola e $14(11,86 \%)$ assistem na casa de amigos ou de parentes 2 . Fica evidente aqui, que quase a totalidade dos estudantes assistem os jogos da Copa na TV, seja com amigos ou com a família. A maioria assiste os jogos em casa. Segundo Gastaldo (2009), a Copa do Mundo de futebol reúne sistematicamente audiências de $97 \%$ de televisores ligados, durante duas horas, assistindo o mesmo programa de TV.

Sobre como os estudantes assistem os jogos e torcem pela seleção, $57(48,30 \%)$ usam camisa da seleção ou roupas nas cores do Brasil, 34 $(28,81 \%)$ usam acessórios nas cores brasileiras, $27(22,81 \%)$ não usam nem roupas e nem acessórios nas cores do Brasil, 26 (22,03\%) torcem com cornetas e outros aparelhos sonoros, 25 (21,18\%) usam bandeira do Brasil ou nas cores verde e amarela, 3 (2,54\%) fazem orações ou simpatias para a seleção brasileira ganhar os jogos.

Podemos perceber que há toda uma preparação para os jogos da Copa, quase $50 \%$ dos estudantes usam camisas da seleção ou roupas verde e amarela, além disto eles usam acessórios nestas cores também. Pouco mais de $20 \%$ usam cornetas e outros aparelhos sonoros e bandeiras do Brasil ou nas cores nacionais para torcer. Como em qualquer

1-A somatória do percentual de respostas ultrapassa $100 \%$ porque os estudantes puderam responder mais de um significado. 
outro ritual, um jogo do Brasil na Copa envolve preparação antecipada, consumos específicos, roupas apropriadas e celebração em grupo, costuma-se assistir aos jogos da seleção brasileira em grupos, seja no escritório, em casa ou num bar (GASTALDO, 2000).

Em outra pesquisa, Gastaldo (2009) realizou uma videoetnografia da recepção coletiva da Copa de 2006 em algumas cidades brasileiras. Ele constatou que o jogo da seleção brasileira na Copa do Mundo é um momento altamente cercado de consumos realizados. A camisa da seleção brasileira é vendida em versões oficiais e não-oficiais. As cores verde e amarelo parecem ser um dos mais poderosos operadores simbólicos de nacionalidade. Em todos os locais de gravação a grande maioria dos torcedores usava alguma peça de roupa ou acessórios nas cores nacionais. No entanto, a atitude dos torcedores em relação ao hino nacional revelou que o padrão apresentado foi de indiferença. No único momento em que o hino foi efetivamente cantado, em Campinas, as imagens mostram claramente uma "apresentação" para os cinegrafistas, podendo ser interpretado mais como uma performance do que uma manifestação de orgulho cívico.

Interrogados sobre o significado da Copa do Mundo, um grupo de estudantes respondeu que o futebol no Brasil é uma paixão nacional, que serve para integrar todos os brasileiros, união de famílias, de torcidas de clubes rivais, de pessoas de todas as raças ou classes sociais.

EF01- "Um momento em que você pode torcer não pelo seu time, mas pelo seu país, um momento em que deixamos de lado nosso time e torcemos pelo nosso país o qual temos orgulho de pertencer".3

EF04- "Um motivo para torcer e vibrar quando o gol sair e chorar quando perde, um sinônimo de uma paixão".

EF08- "Um evento muito importante, pois todo brasileiro é apaixonado por futebol".

EF24- "Uma nação unida por uma paixão. A maior festa brasileira, uma paixão sem fim, é o tempo em que o povo todo para pra assistir uma só coisa".

EM01- "Significa a paixão nacional, no Brasil as pessoas já nascem com as bolas nos pés. Para mim a Copa do Mundo é a hora que todo o país fica unido para torcer para seleção brasileira".

EM30- "Alegria de ver o Brasil em campo; o que faz com que 
mantenhamos o sentimento de sermos brasileiros e nos mantêm reunidos com amigos e familiares".

EM85- "Significa expressar toda emoção e todo amor pela bola, a mistura completa sem diferença de cor ou classe social, a força e alegria de todos faz o futebol brasileiro um dos mais belos do mundo".

De acordo com Daólio (2003), é inegável a influência do futebol na vida nacional a partir do início do século XX. No início se caracterizou como um esporte de elite, mas a partir de meados da década de 1920 ele popularizou-se de tal forma que atinge hoje, direta ou indiretamente, toda a população brasileira. O país mobiliza-se em dias de jogos importantes ou quando a seleção nacional está participando de uma Copa do Mundo. O futebol ocupa no país a posição de esporte número 1 ou paixão nacional4. Ele movimenta as massas e mobiliza a energia torcedora dos brasileiros, assim, é o futebol que acaba atualizando e renovando o espírito de nação, aliás, tão pouco praticado nos últimos anos pelo sofrido povo brasileiro. Conforme DaMatta citado por Gastaldo (2003), o futebol desempenha um papel importante como aglutinador do "povo brasileiro" na sua constituição como nação.

Normalmente, o interesse dos brasileiros pelo futebol divide-se em torno da regionalidade, decorrente da torcida a diferentes clubes. No entanto, este interesse é catalizado numa dimensão "nacional" quando está em campo a "seleção brasileira", que realiza uma espécie de "unidade nacional" em prol de um bem comum: o desempenho do "Brasil" perante os "outros países". Na mídia, o termo "Brasil" é altamente impregnado de sentido metonímico para representar a "seleção brasileira", a "nação" ou o "país", e o termo "seleção brasileira", também utilizado num sentido mais metonímico ainda para representar o "povo brasileiro" (GASTALDO, 2003).

Para Franco Junior (2010, p. 8), a paixão pelo futebol no Brasil não poderia escapar a lógica histórica das Copas, cada uma delas parece despertar o fraco sentimento nacional. Tanto o populismo de esquerda de Goulart celebrou "a vitória da nação" em 1962, quanto a ditadura militar de direita associou-se ao tricampeonato em 1970. Os jogadores brasileiros nunca são simplesmente selecionados, como em outros países, mas "convocados" a servir a pátria. Enquanto os italianos torcem pela Azzurra, os franceses pelos Bleus, os ingleses pelo English Team, os alemães pela National mannshaft, os brasileiros torcem pelo "Bra- 
sil". Ou seja, fazemos pequena distinção entre a seleção de futebol e o país, a vitória ou derrota de um parece ser a do outro.

Outro grupo de estudantes destacaram que os significados da Copa são festa, alegria, comemoração, ou seja, um momento de celebração, como nas seguintes respostas:

EF03- "O Brasil todo em festa".

EF27- "Felicidade para os brasileiros".

EF28- "Época de festa e de comemorar".

EM28- "Muita festa, diversão e a emoção de torcer para o Brasil"

EM46- "Alegria".

EM50- "Muita bebida, muita felicidade, quando o Brasil vence".

EM66- "Festa, alegria, amizade".

De fato, é uma tradição assistir os jogos da seleção brasileira em Copa do Mundo em grupo, seja em casa, em bares e restaurantes ou em parques e locais públicos amplos. Diante da tela da TV ou dos grandes telões instalados em locais públicos, brasileiros se concentram num clima de festa e diversão. Após a vitória da seleção, uma grande concentração de pessoas vai para as ruas comemorar, festejar, seja nas pequenas, médias ou grandes cidades brasileiras.

Outros estudantes destacaram o significado de espetáculo, de competição e de mercadorização relacionado ao mundial de futebol.

EM04- "O maior espetáculo do futebol mundial e confraternização dos países".

EM05- "A escolha da melhor seleção de futebol do mundo".

EM23- "Tempo que o mundo para pelo futebol, todos os países acompanham o maior evento de futebol do mundo".

EM41 - "A melhor competição, a mais disputada e a mais admirada pelos amantes do futebol do mundo todo".

EM59- "O encontro de grandes jogadores e seleções que lutam por um título importantíssimo. E todas que chegam ali são merecedoras".

EM53- "Um grande 'torneio' de futebol, que gera muito dinheiro". 
O futebol é o esporte hegemônico em quase todo o mundo. É de se esperar que a Copa do Mundo seja um dos campeonatos mais importantes, aguardado ansiosamente por muitas nações. O direito de participar de uma Copa é disputado ao longo de vários anos, as eliminatórias sul-americanas para a Copa de 2010 por exemplo, começaram em outubro de 2007. Conforme Franco Junior:

As Copas do Mundo exprimem interesses geopolíticos, daí o número de países ter oscilado de 13 logo após a Depressão (1930) para 16 em 1934, 15 no período pré-Guerra (1938), 13 no pós-Guerra (1950). Entre 1954 e 1978 a fixidez do mapa da Guerra Fria estabilizou a quantia em 16. A posteriori expansão da Comunidade Europeia e ao fim da Cortina de Ferro correspondeu ao alargamento do mundo futebolístico, com 24 países presentes entre 1982 e 1994 e 32 a partir de 1998. (...) graças aos interesses da crescente globalização, a África, a partir de 1982, contou com duas seleções, em 1994 com três, desde 1998 com cinco. A Ásia compareceu em 1938, este presente em cinco das oito Copas realizadas entre 1954 e 1982, mas a partir de 1986 ganhou duas vagas fixas, que subiram para quatro desde 1998 (FRANCO JUNIOR, 2010, p. 8).

A Copa também é um grande negócio e envolve muito dinheiro, mas nem sempre os países organizadores é que ficam no lucro. A FIFA exige uma série de garantias governamentais e isenção tributária sobre todas suas atividades no país, o fator "risco" é todo do país sede e o "lucro" é da FIFA que recebe milhões (em direitos de transmissão, patrocinadores etc.) sem risco algum (MARMO, 2010).

Já outro grupo de estudantes destacou os significados de união de diferentes culturas e de promoção da paz através do futebol.

EM06- "A união de culturas em um só local, união dos povos".

EM27- "Significa paz entre os povos".

EM33- "É a forma de confraternização entre os países".

EM37- "Campeonato que reune (sic.) muitas pessoas e promove a paz".

EM44- "Um encontro de culturas e nacionalidades diferentes".

EM61 - "A união dos países".

EM62- "Um encontro cultural, mistura de nacionalidades". 
As Copas do Mundo colocam em contato diferentes culturas segundo o depoimento dos estudantes. Mesmo sem ir assistir os jogos in locu, através da tela da TV podemos conhecer um pouco mais o país sede, suas principais cidades, clima, vegetação, fauna, geografia, economia, cultura, entramos em contato com o modo de vida das seleções que se confrontam no campeonato mundial. De acordo com Franco Junior (2010), as Copas do Mundo são rico observatório cultural.

Em relação ao significado do esporte ou da Copa promovendo a paz entre os povos, isto nos remete aos jogos olímpicos da Grécia Antiga, nos quais todas as guerras cessavam durante o período das disputas. Além disto, nos remete também ao discurso da nova função do esporte no mundo, divulgado pela ONU nas suas Metas para o Milênio:

O esporte pode atravessar as barreiras que dividem as sociedades, tornando-o assim uma poderosa ferramenta para apoiar esforços de prevenção de conflitos e de construção da paz, tanto simbolicamente no nível global, quanto de maneira bastante prática dentro das comunidades. Quando aplicados eficazmente, os programas de esportes promovem a integração social e fomentam a tolerância, ajudando reduzir a tensão e gerar diálogo. O poder de organização e reunião do esporte o torna uma ferramenta ainda mais eficaz para a comunicação e a conscientização (ONU, 2003).

Ainda sobre o significado de paz associado a Copa, Marmo (2010) lembra que os hondurenhos deixaram suas diferenças de lado na noite em que o país se classificou para a Copa, e as ruas ficaram lotadas com a comemoração. Do mesmo modo, na Sérvia, a classificação para o mundial de futebol propiciou raro momento de unidade e orgulho nacional. No entanto, nas Copas também emergem diferentes rivalidades, nem tudo é paz e união. Em 1930, o consulado uruguaio foi atacado em Buenos Aires por argentinos inconformados pela derrota para o país vizinho. A partida entre a Áustria e a Hungria em 1938 foi uma verdadeira batalha, refletindo as tensões não resolvidas de longas décadas em que as duas nações tinham vivido politicamente unidas e culturalmente afastadas. Em 1950 a Argentina se recusou a participar da Copa porque ela foi realizada no Brasil (FRANCO JUNIOR, 2010). 
Outros estudantes ressaltam que a Copa do Mundo é um momento de sentir orgulho por ser brasileiro.

EF03- "É querer e poder presenciar esse momento em alegria e emoção com todos e ter o orgulho de ser brasileiro".

EF27- "Alegria, significa quase tudo, sentir-se feliz e orgulhoso do seu país".

EF29- "Tanto como brasileiro, como para outras onde todos esperam com ansiedade de ver seu país entrar em campo e muitas vezes se sentir um vencedor, melhor que os outros. Uma forma de amor, garra e orgulho de seu próprio país".

EM03- "O momento de honrar a sua nação torcendo e defendendo o seu país".

No período deste grande evento esportivo, podemos observar que brasileiros de todos os cantos do país exibem com mais orgulho as cores nacionais de diversas formas. Gastaldo (2000) considera que a Copa do Mundo representa o verdadeiro momento de celebrar a nacionalidade para os brasileiros, ao contrário dos desfiles cívicos de Sete de Setembro, que lembram muito mais a memória da ditadura militar. De acordo com Helal, Cabo e Silva (2010, p. 2), "não se identifica, na atualidade, por exemplo, fatores históricos capazes de reunir os brasileiros em torno de uma mesma e compartilhada consagração".

Para alguns estudantes, a Copa do Mundo significa obrigação de ganhar e o favoritismo da seleção brasileira.

EF02- "Uma oportunidade de seu país se destacar no que realmente é bom, porque quase todos os brasileiros adoram futebol e são bons na sua prática".

EM02- "Mais uma conquista mundial".

EM15- "Tudo, pois o Brasil é o país do futebol".

EM41- "Significa: obrigação, porque a Copa do Mundo é uma forma de mostrar aos outros quem realmente é o melhor".

EM47- "Tudo, somos pentacampeões".

EM57- "Festas, alegria e principalmente ganhar a Copa".

Conforme Gastaldo (2003), grande parte da ligação da cultura brasileira contemporânea com o futebol se deve a bem sucedida participação brasileira na Copa do Mundo. Realizada desde 1930, o Brasil é 
o país com maior número de títulos e o único a participar de todas as edições. Os eventos ocorridos durante as Copas do Mundo fazem parte de um "passado mítico" da cultura brasileira. Em uma Copa do Mundo os participantes não são meros times de futebol, mas "seleções nacionais", uma espécie de "encarnação simbólica" de cada nação participante. Assim, a Copa é uma chance de colocar a própria nação em perspectiva comparada com o resto do mundo. No Brasil, a Copa do Mundo é o apogeu do mundo dos esportes, sendo dada mais importância do que as Olimpíadas, afinal quem vence a Copa é, incontestavelmente o "melhor do mundo". Bitencourt (2009) destaca que nosso principal rito de autoridade é "Você sabe com quem está falando? Nós somos pentacampeões do mundo". Gastaldo lembra que o tetracampeonato deu ao Brasil uma salvaguarda contra a derrota. Na Copa de 1998, "mesmo a derrota para a França na decisão do torneio não impediu a atribuição de significados positivos à seleção, como a melhor do século ou campeã do século" (GASTALDO, 2003, p. 5).

Apenas um dos estudantes lembrou que além da Copa este é um ano de eleições: AM19- "Um evento em que para o país, quando tem Copa do Mundo tem eleição, ou seja, o ano que marca muito o país". Percebe-se certo grau de consciência política, que apesar da festa e das comemorações em torno da Copa, este é um momento decisivo para o país, para escolher o próximo presidente da República, governadores, senadores e deputados. Ainda que ele não tenha desenvolvido muito sua ideia, entendemos que o momento da Copa não pode afetar a discussão dos problemas sociais e as propostas para a construção de um país melhor.

\section{Considerações finais}

Os resultados da pesquisa evidenciaram uma forte ligação dos alunos do Ensino Médio com a mídia, o futebol, a Copa do Mundo e o nacionalismo. Grande parte dos estudantes tem o hábito de assistir jogos de futebol na TV. Mais de dois terços deles leem matérias sobre futebol em jornais, revistas ou Internet, mas numa frequência menor do que assistem futebol na TV. Pouco mais de $80 \%$ dos estudantes têm o hábito de jogar futebol, percentual menor do que o de estudantes que veem o futebol pela TV. Os significados que atribuem a prática do futebol estão mais associados à saúde e ao lazer. Praticamente todos os alunos assistem aos jogos da Copa pela TV, com os amigos ou 
a família, a maioria assiste em casa. Há uma preparação para assistir aos jogos da Copa, quase metade dos estudantes usam camisas da seleção ou roupas verde e amarela.

Os significados da Copa para os estudantes são: uma paixão nacional, que serve para integrar todos os brasileiros, união de famílias, de torcidas de clubes rivais, de pessoas de todas as raças ou classes sociais; festa, alegria, comemoração, um momento de celebração; espetáculo, competição e mercadorização; união de diferentes culturas e de promoção da paz; momento de sentir orgulho por ser brasileiro; obrigação de ganhar e o favoritismo da seleção brasileira.

Como se viu, existe um forte vínculo dos estudantes com o futebol, a Copa do Mundo e o Nacionalismo, em grande parte fomentado pela mídia. Num momento posterior, cabe refletirmos criticamente junto com os estudantes sobre esta relação, em especial o fenômeno do nacionalismo cíclico em épocas de Copa, a identificação da seleção com o país, e do país com o povo brasileiro e sua autoestima, a construção dos heróis esportivos, a corrupção no esporte, o caráter mercadológico e os interesses econômicos que estão por trás deste grande evento esportivo. Com a Copa do Mundo de 2014 e as Olimpíadas de 2016 no Brasil, cabe ainda acompanhar os investimentos e possíveis desvios de verbas na realização dos eventos, afinal é o dinheiro do povo brasileiro que está sendo gasto. Tudo isto pode ser tema de estudo na Educação Física escolar. No momento, estamos dando continuidade a pesquisa, fazendo a leitura crítica de algumas publicidades da Copa e desenvolvendo um blog para dialogar com os alunos sobre temas correlatos. Esperamos apresentar estes dados numa próxima oportunidade.

Habits and meanings related to media, soccer, world cup and nationalism for high school students

\begin{abstract}
Our goal was to understand the relationship of high school students with the media, football, World Cup and nationalism. We applied a questionnaire to 120 students infour classes in the 1st year of high school IFMT, São Vicente campus. Based on dataanalysis, we concluded that students have the habit of watching football matches on TV, especially at the WorldCup, and football practice less (even in a high percentage) of what they see. The meanings of the Cup is a national passion, marriage, party, peace, performance, pride, duty to victory.
\end{abstract}

Keywords: Media - World - Cup - Nationalism 
Hábitos y significado relacionados a los medios, la copa mundial de futbol, y el nacionalismo para nacionalismo para estudiantes de secundaria

\section{Resumen}

Nuestro objetivo era entender la relación de estudiantes de secundaria con los medios de comunicación, el fútbol, la Copa del Mundo y el nacionalismo. Se aplicó un cuestionario a 120 estudiantes en cuatro clases en el 1er año de IFMT la escuela secundaria, el campus de São Vicente. Con base en el análisis de datos, llegamos a la conclusión de que los estudiantes tienen la costumbre de ver los partidos de fútbol en la televisión, especialmente en la Copa Mundial, y la práctica de fútbol menor (incluso en un alto porcentaje) de lo que ven. Los significados de la Copa es una pasión nacional, el matrimonio, en una fiesta, la paz, el rendimiento, el orgullo, el deber de la victoria.

Palabras clave: Medios de Comunicación - Copa del Mundo - Nacionalismo

\section{Referências}

BETTI, M. Educação Física Escolar: ensino e pesquisa-ação. IjuíRS: EdUnijuí, 2009.

BITTENCOURT, F. G. Esboço sobre algumas implicações do futebol e da Copa do Mundo para o Brasil: identidade e ritos de autoridade. Revista Brasileira de Ciências do Esporte, Campinas, v. 30, n. 3, p. 173-189, maio 2009.

DAOLIO, J. Cultura: Educação Física e futebol. 2 ed. rev. e ampl. Campinas: EdUnicamp, 2003.

FERRÉS, J. Televisão e Educação. Porto Alegre-RS: ArtMed, 1996.

FRANCO JUNIOR, H. Futebol e orgulho nacional. Le Monde Diplomatique Brasil. Ano 3, n. 35, p. 8, junho de 2010.

GASTALDO, É. L. A nação e o anúncio: a representação do "brasileiro" na publicidade da Copa do Mundo. Tese de doutorado. Campinas-SP: Instituto de Artes da Unicamp, 2000.

. Futebol, mídia e sociedade no Brasil: reflexões a partir de um jogo. Cadernos IHU Idéias. São Leopoldo-RS, Ano 1, n. 10, p. 1-24, 2003.

. Ritos da nação: uma vídeoetnografia da recepção coletiva da 
Copa do Mundo no Brasil. Revista Brasileira de Ciências do Esporte. Campinas, v. 31, n. 1, p. 209-222, setembro 2009.

HELAL, R.; CABO, A. do; SILVA, C. Pra frente Brasil! Comunicação e identidade brasileira em Copas do Mundo. Esporte e Sociedade. Ano 5, n. 13, p. 01-21, nov. 2009/fev. 2010.

KFOURI, J. "O Brasil não é o país do futebol”. Le Monde Diplomatique Brasil. Ano 3, n. 35, p. 4-5, Junho de 2010.

MARMO, S. F. G. Autoestima dos brasileiros. Le Monde Diplomatique Brasil. Ano 3, n. 35, p. 10, Junho de 2010.

ONU. Relatório da Força Tarefa entre Agências das Nações Unidas sobre o Esporte para o Desenvolvimento e a Paz: Em direção às Metas de Desenvolvimento do Milênio. 2003.

PIRES, G. De L. Cultura esportiva e mídia: abordagem crítico-emancipatória no ensino de graduação em Educação Física. In: BETTI, M. (org.). Educação Física e mídia: novos olhares, outras práticas. São Paulo: Hucitec, 2006, p. 19-44.

Recebido em: 15/02/2011

Revisado em: 25/04/2011

Aprovado em: 13/09/2011

Endereço para correspondência

mrgodoi78@hotmail.com

Marcos Roberto Godoi

Faculdade Aum

Avenida Dom aquino $n^{\circ} 38$

Centro - Cuiabá-MT

CEP:78015-200 - Brasil 